WellBeing International

WBI Studies Repository

2011

\title{
Microclimate Preferences of the Grey-Headed Flying Fox (Pteropus poliocephalus) in the Sydney Region
}

\author{
Stephanie T. Snoyman \\ Macquarie University \\ Culum Brown \\ Macquarie University
}

Follow this and additional works at: https://www.wellbeingintlstudiesrepository.org/acwp_asie

Part of the Animal Studies Commons, Nature and Society Relations Commons, and the Population Biology Commons

\section{Recommended Citation}

Snoyman, S., \& Brown, C. (2011). Microclimate preferences of the grey-headed flying fox (Pteropus poliocephalus) in the Sydney region. Australian Journal of Zoology, 58(6), 376-383.

This material is brought to you for free and open access by WellBeing International. It has been accepted for inclusion by an authorized administrator of the WBI Studies Repository. For more information, please contact wbisr-info@wellbeingintl.org.

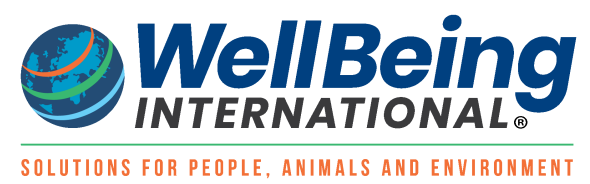




\title{
Microclimate preferences of the grey-headed flying fox (Pteropus poliocephalus) in the Sydney region
}

\author{
Stephanie Snoyman and Culum Brown \\ Macquarie University
}

KEYWORDS

bat, behaviour, conservation, roost selection, urban ecology

\begin{abstract}
The population size of the grey-headed flying fox (Pteropus poliocephalus) has decreased dramatically as a result of a variety of threatening processes. This species spends a great proportion of time in roosting large social aggregations in urban areas, causing conflict between wildlife and humans. Little is known about why these bats choose to roost in some locations in preference to others. Roost selection by cavedwelling bats can be greatly influenced by microclimatic variables; however, far less is known about microclimate selection in tree-roosting species despite the direct management implications. This study aimed to determine the microclimate characteristics of $P$. poliocephalus camps. Temperature and humidity data were collected via data-loggers located both in six camps and the bushland immediately adjacent to the camps in the greater Sydney region. We found significant differences between the microclimate within the camps and the surrounding bushland. In general, areas within the camps had a greater variance in temperature and humidity than the alternative locations. We hypothesise that camps may be specifically located in areas with high microclimate variance to accommodate a range of individual preferences that vary depending on demography.
\end{abstract}

\section{Introduction}

Flying foxes roost in large social aggregations hereafter referred to as 'camps'. It has been suggested that camps provide resting habitat and shelter, as well as acting as sites for social interactions and information exchange (Ratcliffe and ter Hofstede 2005). Camps may also provide protection from predators and favourable microclimatic conditions, particularly during the breeding season (Kunz 1982; Kalko et al. 2006). Bat camp selection is, therefore, likely influenced by a range of sociocultural, biotic and abiotic factors and have a significant impact on species survival (Parry-Jones 1987; Hall and Richards 1991; Entwistle et al. 1997).

One of the outstanding enigmas in the management of flying foxes is why the camps are positioned in certain locations in preference to others. This is of concern for several reasons, not least of which is trying 
to understand the basic habitat requirements of these highly charismatic, threatened species. When camps are disturbed, the bats leave for a time but often return to the same location. Such observations suggest that there is something specific about these locations to which the bats are attracted. Moreover, owing to a range of factors, including habitat destruction and an increased food availability in cities, bat camps are increasingly common in urban areas, causing conflict with the local inhabitants.

Some camps have been permanently occupied for decades while others are entirely transient (Lunney and Moon 1997). Within the permanently occupied camps, some camp members are considered residents while others are nomadic, moving from camp to camp presumably in response to shifts in regional food abundance (Williams et al. 2006). This movement between camps facilitates social and mating opportunities between camps (Eby 1991b). Large-scale migrations and movements between camps leads to gene flow between populations (Baldwin 2010). Thus, despite their wide distribution, it is apparent that all flying fox camps need to be managed collectively as a single population.

The grey-headed flying fox (GHFF) (Pteropus poliocephalus), a species of Old World fruit bat, is a visually distinct, gregarious and highly mobile mammal and is one of the largest bats in the world (Markus and Blackshaw 2002; Forsyth et al. 2006). The geographical range of this Australian endemic was historically warm-temperate to tropical (Parris and Hazell 2005); however, the northern boundary of its distribution has shifted by $\sim 750 \mathrm{~km}$ south since the 1930s (Tidemann 1999), making it the most southerly distributed of all Pteropus worldwide (Peacock 2004). The distribution now extends from Bundaburg (243' $\mathrm{S}$ ) to Warrnambool (38 $\left.10^{\circ} \mathrm{S}\right)$, a distance of over $1700 \mathrm{~km}$. The species is a dietary generalist, feeding on a variety of fruits, nectar and pollen (McDonald-Madden et al. 2005). They make nightly forays up to $50 \mathrm{~km}$ in search of food and return to a communal camp to rest during the day (Eby 1991b). Consequently, flying foxes provide several important ecosystem services including assisting forest regeneration and maintenance of floral biodiversity through long-distance pollination (Eby 1991a, 1995; Hall and Richards 2000) and seed dispersal (Puddicombe 1981; Eby 1991a; Fujita and Tuttle 1991).

The distribution of $P$. poliocephalus corresponds to the region of highest human density in Australia. Besides the historical conflict between bats and fruit growers, by whom the bats are considered pests and managed accordingly (Hall and Richards 1987), there is an increase in the number of interactions between humans and flying foxes in urban areas that has led to additional conflict (Eby 2006). In Queensland licences are issued to horticulturalists to shoot flying foxes in an attempt to reduce their numbers and protect crops. In urban areas, public concern has intensified over issues such as noise, the odour of roosting camps, property value, land use and human health (Smith 2002). For example, flying foxes have recently been evicted from both the Melbourne and Sydney Botanic Gardens because of the damage they have inflicted on trees. Hence flying fox conservation remains a complex and multifaceted management concern.

In 1932, Ratcliffe estimated that the number of $P$. poliocephalus on the east coast of Australia was in the order of 'many millions' (Dickman and Fleming 2002). Today, published counts estimate the population to be in the order of 300000 Australia-wide (Welbergen 2005). As GHFFs produce only a single offspring per breeding season, generally conceived in March-April and birthed in September-November, population numbers increase at a particularly slow rate. Over the last decade the GHFF population is estimated to have declined by 35\% (Eby and Lunney 2002; Martin and Mcllwee 2002). The decrease in GHFF population size appears to be a common theme among the flying foxes, with $48 \%$ of the 61 species in the genus listed as threatened on the IUCN red list (IUCN 2010). This decrease in population size has been attributed to a range of threatening processes including a loss of foraging and roosting habitat due to clearance of native vegetation for agriculture, forestry and urban development (Duncan et al. 1999). These impacts have been further exacerbated by temperature extremes associated with climate change (Welbergen et al. 2008). As a result, the GHFF has been listed as 'vulnerable' under the 
Commonwealth Environment Protection and Biodiversity Conservation Act 1999 (Eby and Lunney 2002) and by IUCN red list (IUCN 2010) initiating a controversial shift in the management goals from pest management towards conservation (Eby and Lunney 2002).

Initial studies of $P$. poliocephalus camps suggest that certain habitat characteristics such as proximity to water sources as well as vegetation structure may be important features in camp selection (Hall and Richards 2000; Eby 2002). These habitat characteristics are likely to impact on microclimate variables within the camp such as air temperature and relative humidity. Several studies on a variety of bat species have suggested that microclimate variables are important in camp selection (Kunz 1982;Law1993) and may have direct fitness outcomes (Entwistle et al. 1997). This is particularly the case in cave-dwelling species that prefer locations with a well defined range in temperature and humidity (Dwyer 1971; Baudinette et al. 1994; Kunz and Lumsden 2003). The thermoregulatory properties of potential camp locations, therefore, is thought to be one of the key driving forces behind camp selection (Sedgeley 2001; Willis and Brigham 2005; Turbill 2006). Currently, little research has been carried out to determine the microclimate characteristics of camps of $P$. poliocephalus.

The aim of this study was to determine the microclimate characteristics of $P$. poliocephalus camps within the greater Sydney region. In particular, we compared the microclimate within camps with that of the surrounding bushland using data loggers.

\section{Materials and methods}

\section{Study site}

Fieldwork was conducted in six locations within the greater Sydney region. These locations included

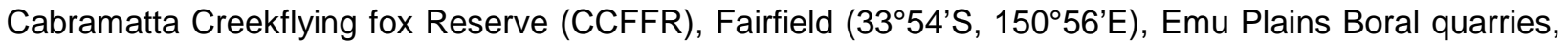
Penrith ( $\left.33^{\circ} 44^{\prime} \mathrm{S}, 150^{\circ} 40^{\prime} \mathrm{E}\right)$, Kurnell water desalination plant, Sutherland (340.' $\left.\mathrm{S}, 151^{\circ} 12^{\prime} \mathrm{E}\right)$, Ku-ring-gai flying fox Reserve (KFFR), Gordon ( $33^{\circ} 45^{\prime} S$, $151^{\circ} 09^{\prime} E$ ), Sydney Royal Botanic Gardens (SRBG), Sydney

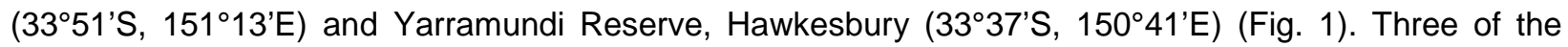
locations were permanently occupied camps (KFFR, SRBG, CCFFR) whereas occupancy at the other three varied depending on local food availability (Yarramundi, Emu Plains, Kurnell). Depending on the season, the camps contained various numbers of bats, varying from up to 9000 at Kurnell, 30000 at CCFFR, 30000 at Emu Plains, 69000 at KFFR, 8000 at SRBG and 10000 at Yarramundi. Collectively, these camps are home to a significant proportion of the species' total population. For full details on patch sizes, vegetation types and habitat structures at each location, see Snoyman (2008).

The six camps were surveyed between March 2007 and January 2008, encapsulating the breeding season of the species. At each location, the core of the roosting area in the camp was identified based on long-term observations of the distribution of roosting animals. Twenty data loggers (iButton Hygrochron DS1923, Dallas Semiconductor, Dallas, TX, USA) measuring temperature $\left({ }^{\circ} \mathrm{C}\right)$ and relative humidity, were installed on various trees at all camps except for Yarramundi, during July 2007. At Yarramundi Reserve a variety of data loggers were installed due to financial restrictions; 20 data loggers (iButton Thermochron DS1921, Dallas Semiconductor, Dallas, TX, USA) measured temperature only, and a further 16 data loggers (AZ8829 HLP Controls) measured both temperature and humidity. Sixteen HLP data loggers were attached to ibutton temperature-only data loggers and affixed to the trees to enable calibration of the various types of data loggers and the remaining four temperature data loggers were attached alone. At each location, half the data loggers were placed in trees frequently occupied by the GHFFs and the remaining half in trees where bats were never observed roosting (i.e. in the surrounding bushland outside the long-term roosting area but still in the reserve). 
A random number generator was used to determine which trees housed the data loggers in the camp and surrounding bushland. The tree species were identified, flagged and a GPS coordinate was recorded. In all but one location, fishing line was shot over a branch on the target tree with the use of a bow and arrow. The fishing line was then tied to string that was hauled over the branch and back to the ground. The ends of the string were tied to each other and to the data logger so it could be raised like a flag to a height where the bats were repeatedly observed roosting. An inclinometer was used to measure the height of the data logger in each tree. At the SRBG a cherry picker was used to place the data loggers in selected trees. All data loggers were set to record at two-hourly intervals for a 24-h period. Data were collected at intervals less than 170 days, which represented the memory limit of the loggers. In total, 136 loggers were deployed across the six locations. No data loggers were replaced during the study.

In order to minimise welfare impacts and lessen the disturbance on this species, entry into the camps was kept to a minimum; when entry was essential only a small number of individuals entered the camps. Field officers also limited the amount of noise they produced and wore camouflaged clothing.

\section{Variables and statistical analysis}

In total, we placed 136 data loggers across the six camps, recording climate variables at two-hourly intervals. To reduce the potential for autocorrelation relating to repeated recordings of climate variables at the same location throughout the observation period, we calculated daily mean, minimum, maximum and variance (maximum-minimum) values for temperature and humidity for each logger. We then averaged the data across three seasons (Winter, Spring and Summer). We chose seasons as the temporal variable because it likely has greater biological relevance than daily shifts in climate variables. These variables were entered into the model to determine the microclimate preferences. As all the data were normally distributed, a General Linear Model (SPSS 15.0, Chicago, IL) was used to analyse the data. The independent variables considered in the model included camp identity and position (referring to data loggers placed in the core roosting areas of the camps and those on the periphery of the camps) and season was included as a repeated measure. Each microclimate variable was examined in isolation.

In the second analysis we removed camp identity and replaced it with information regarding the occupancy status of each location (permanent camp or transient camp).

The patch size (conservation area) of the bushland housing the camps was not included in our analyses because regression analysis showed that this variable did not contribute substantially to the variation seen in the microclimatic variables $\left(r^{2}<0.01\right.$ in all cases $)$.

\section{Results}

Complete temperature and humidity data were obtained from only 112 data loggers as a result of missing or faulty data loggers. The missing or faulty data loggers were evenly distributed across the sample camps. Given our primary interest in the differences in microclimate variables between the core of the camps and the surrounding bushland, we present only the results of the main effects and any significant interaction involving logger position. Similarly, in the second analysis we report only the differences relating to camp occupancy status.

\section{Analysis of camp location}

No significant differences in mean daily temperatures were observed between the roost and the surrounding reserve. The camps had significantly higher maximum daily temperatures $\left(\sim 1^{\circ} \mathrm{C}\right)$ than surrounding bushland(RMANOVA: $F_{1,101}=15.537, P<0.001$ ). This difference varied depending on the location of the roost (RMANOVA: $F_{5,101}=14.803, P=0.005$ ). The general trend held true for all locations 
except Kurnell, where the maximum daily temperature in the bushland surrounding the reserve was slightly, though not significantly, warmer than the roost. The minimum daily temperatures within the roosts were significantly lower $\left(<1^{\circ} \mathrm{C}\right)$ than in the surrounding bushland (RMANOVA: $F_{1,101}=16.253, P<0.001$ ). This general pattern occurred throughout the three seasons although the magnitude of the difference varied slightly between seasons (RMANOVA: $F_{2,202}=3.828, P<0.023$ ). The roost had significantly greater variance in daily temperatures $\left(\sim 1.3^{\circ} \mathrm{C}\right)$ than the surrounding reserve (RMANOVA: $F_{1,101}=4.211$, $P=0.043$ ) (Fig. 2).

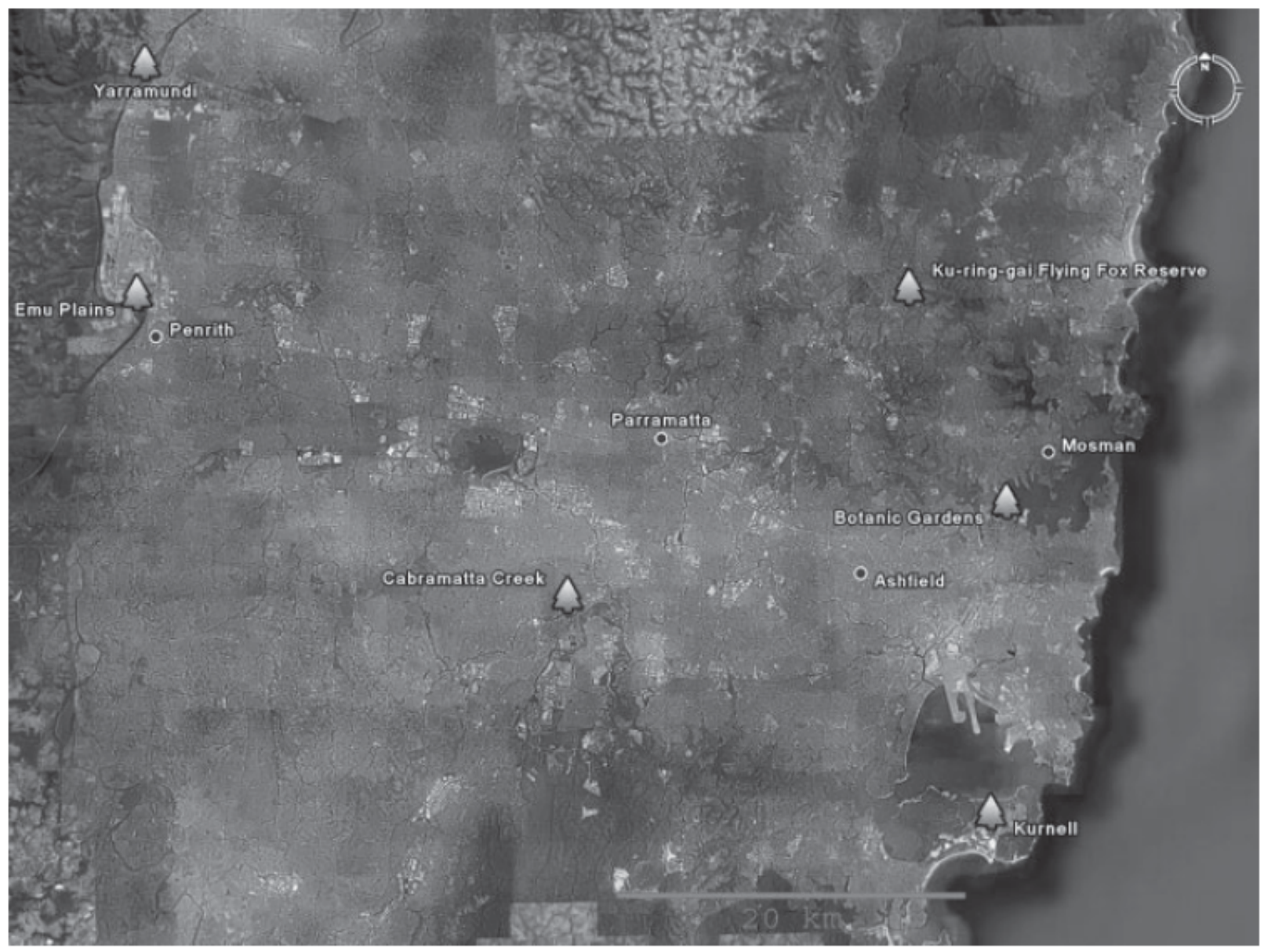

Fig. 1. Map detailing the locations of the six flying fox camps in the Greater Sydney region. The Botanic Gardens camp is near the centre of the central business district.

In both Winter and Spring the mean humidity was higher in the roost than in the surrounding bushland whereas the opposite was true in the Summer(RMANOVA: $F_{2,178}=4.585, P=0.011$ ). The roost tended to have a higher daily maximum relative humidity than the surrounding bushland, although not significantly so (RMANOVA: $F_{1,101}=3.184, P=0.078$ ). The magnitude of this difference varied depending on the season (RMANOVA: $F_{2,178}=6.058, P=0.003$ ), the difference being greatest in Winter and Spring. No significant differences were observed in daily minimum relative humidity between the roost and the surrounding reserve. The variance in humidity was significantly greater $(\sim 2.2 \%)$ in the roosts than in the surrounding reserve (RMANOVA: $\left.F_{1,101}=8.765, P=0.004\right)$ (Fig. 3 ). 


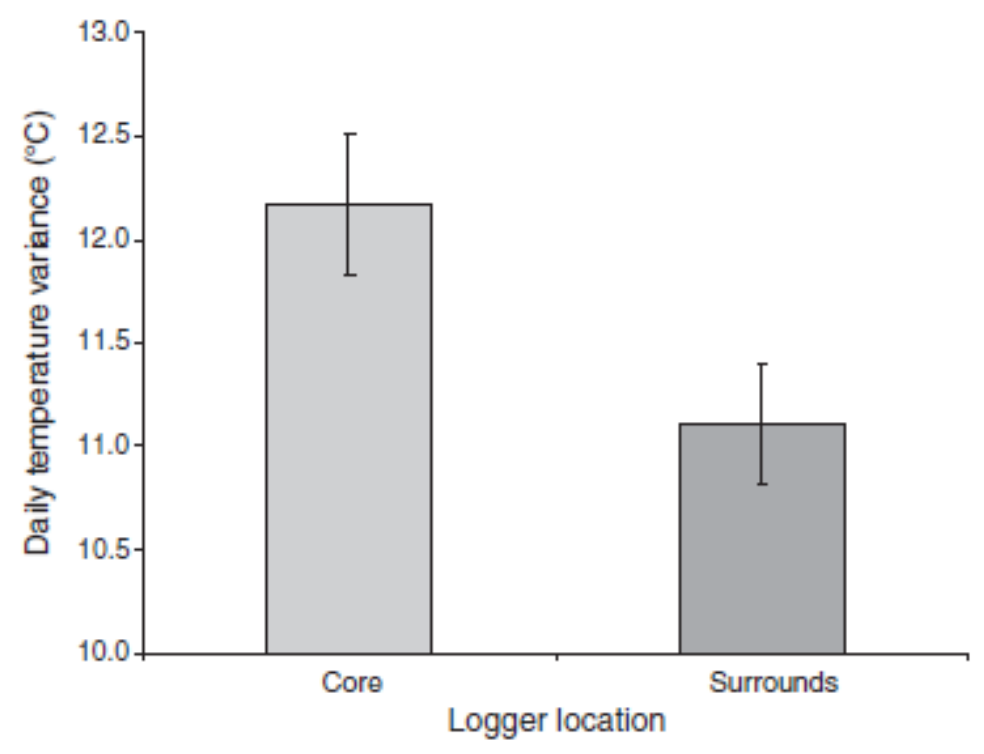

Fig. 2. The mean ( \pm s.e.) variance in daily temperatures in the roost and the surrounding bushland.

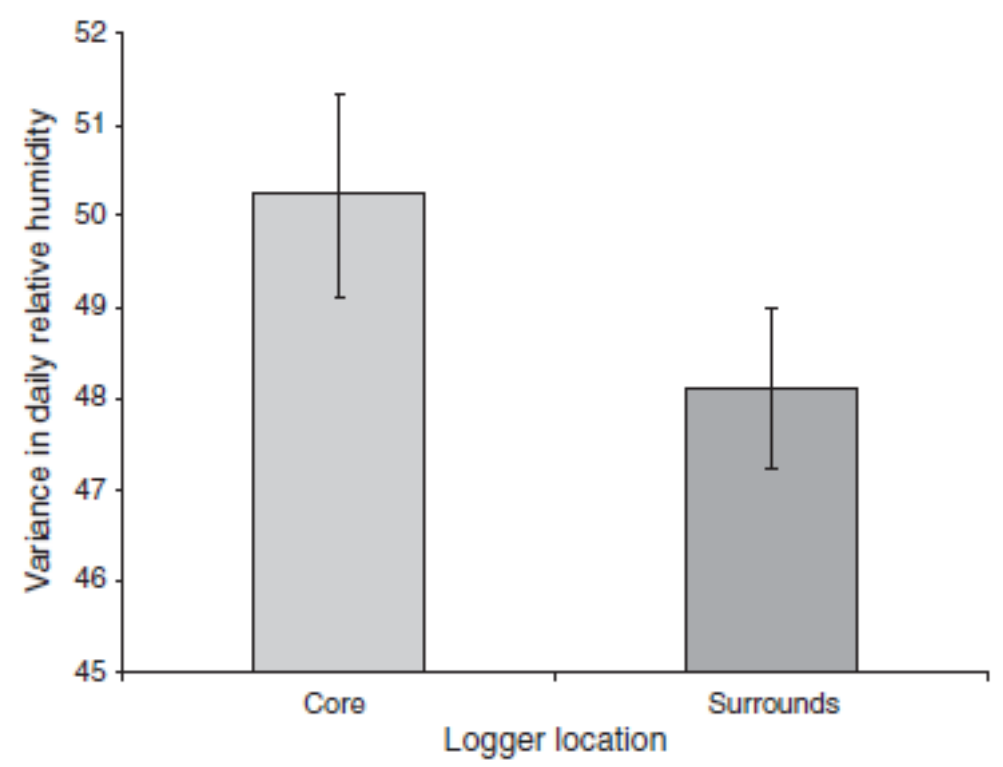

Fig. 3. The mean ( \pm s.e.) variance in daily relative humidity in the roost and the surrounding bushland.

\section{Permanent versus transient camps}

In Winter and Spring permanently occupied camps had higher mean daily temperatures whereas no difference was observed in Summer(RMANOVA: $\left.F_{2,218}=9.348, P<0.001\right)$. In all cases the difference was less than $1^{\circ} \mathrm{C}$. Maximum daily temperatures were significantly higher $\left(\sim 1.6^{\circ} \mathrm{C}\right)$ in the core areas than in the surrounding bushland in the permanently occupied camps but no difference was observed in the transient camps (RMANOVA: $F_{1,109}=8.950, P=0.003$ ). In Winter and Spring permanently occupied camps had higher minimum daily temperatures (i.e. it was $\sim 1^{\circ} \mathrm{C}$ and $0.5^{\circ} \mathrm{C}$ warmer respectively) than did transient camps whereas no difference was observed in Summer (RMANOVA: $F_{2,218}=3.828, P<0.023$ ). 
The permanently occupied camps had significantly greater variance in daily temperatures $\left(\sim 8.4^{\circ} \mathrm{C}\right)$ than did transient camps (RMANOVA: $F_{1,109}=52.667, P<0.001$; Fig. 4). This general pattern varied slightly between seasons, with the greatest difference between permanent and transient camps being observed in the Spring and Summer (RMANOVA: $F_{2,218}=14.504, P<0.001$ ).

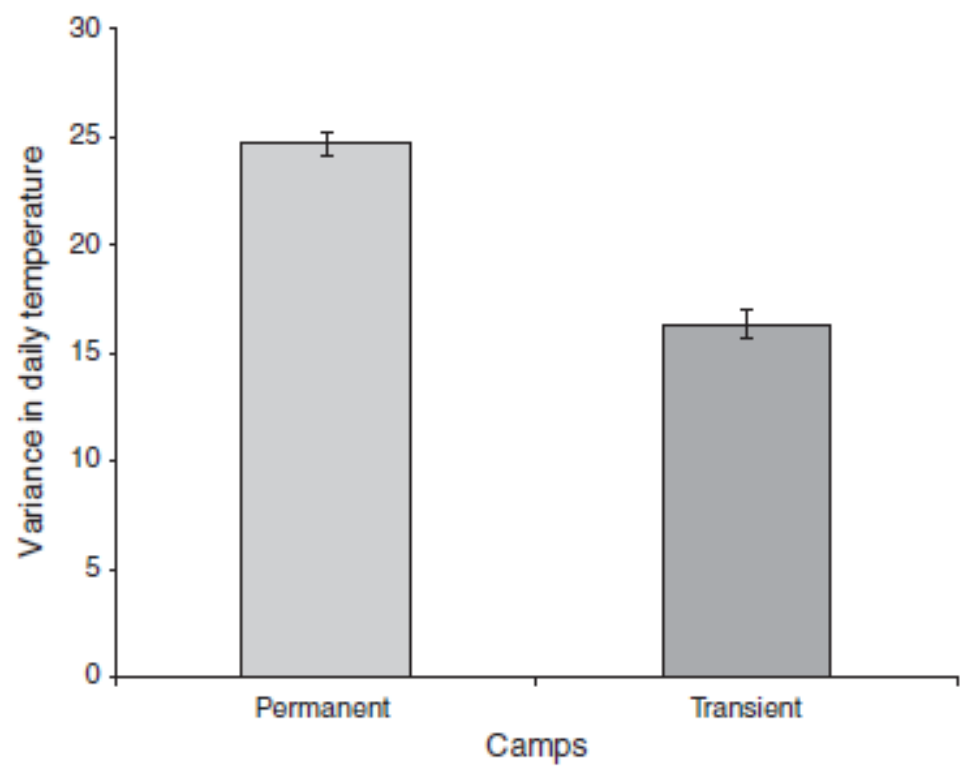

Fig. 4. The mean( \pm s.e.) variance in daily temperature between permanently occupied and transient camps.

The mean daily relative humidity was lower in the permanent roosts than in the transient roosts $(\sim 1.5 \%$; RMANOVA: $\left.F_{1,97}=5.778, P=0.018\right)$. In Winter the permanently occupied camps had significantly lower daily maximum relative humidity $(\sim 1.5 \%)$, which was reduced somewhat in the Spring $(\sim 1 \%)$ and there was no difference in the Summer (RMANOVA: $F_{2,194}=8.288, P<0.001$ ). Permanent camps had slightly lower daily minimum relative humidity than did transient camps $\left(\sim 2.5 \%\right.$; RMANOVA: $F_{1,97}=3.842, P=$ 0.053). The difference was significant in both Winter and Spring but not in Summer (RMANOVA: $F_{2,194}=$ 3.889, $P=0.022$ ). No significant differences were observed in daily relative humidity variance between the permanent and transient camps.

\section{Discussion}

Studies conducted on bats, particularly microbats, have suggested that a specific combination of microclimatic variables may play a vital role in the camps of many bat species (Churchill et al. 1997; Kalcounis and Brigham 1998; Sedgeley 2001) whereas for other bats species, microclimatic variables within camps are suggested to be less important (Baudinette et al. 2000; Willis and Brigham 2007). Flying foxes, being significantly larger bats, are thought to be less susceptible to variation in external conditions but the data presented herein challenge this notion. Our results suggest that camp microclimate may have a significant effect on the GHFF, indicating that the thermal regime of their immediate roosting environment is likely an important factor influencing their energy expenditure (McNab 1982). The current study shows that both temperature and humidity play a role in determining camp selection in the GHFF. In particular, the core areas of GHFF's camp locations have a higher variance in temperature and humidity relative to the surrounding peripheral areas. Similarly, permanently occupied camps have far greater variation in daily temperatures than transient camps. 
The fact that the difference between the camp microclimate and the surrounding bushland held true for all of the camps with subtle variations between camps is somewhat remarkable given the vastly different geographic locations of the camps we sampled. In only one instance did we find significant interactions with camp identity (maximum daily temperature) and in that case only one location did not follow the general trend. Each camp is subject to the larger-scale weather patterns of the area. The Kurnell camp, for example is on a relatively thin peninsula between the Tasman Sea and Botany Bay (Fig. 1), thus the microclimate within the camp is subject to coastal fluctuations in temperature and humidity which are, to some extent, buffered by sea surface temperatures. The camp at Emu plains, by contrast, is over $60 \mathrm{~km}$ inland and this area is subject to higher daily maxima, lower nightly minimum temperatures and lower humidity than coastal areas.

One of the primary results from this study is that the bat camps have a larger variance in temperature and humidity than the surrounding bushland (Figs 2 and 3), which at first glance appears somewhat counterintuitive given the high specificity for microclimate in cave- and hollow-dwelling species (Baudinette et al. 1994, 2000; Churchill et al. 1997). However, flying foxes are very large bats and probably capable of maintaining some degree of thermal homeostasis in comparison with microbats. Moreover, they are relatively active during the day and can move within the roost if necessary. It has been demonstrated, however, that the thermoregulatory needs and microclimatic requirements of microchiroptera vary with season, age, sex (Churchill et al. 1997) and reproductive class of bat (Willis and Brigham 2004) thus there is no single optimal location that serves the different energetic needs throughout the year or during different reproductive phases (Kerth et al. 2001). It is likely that a similar explanation holds true for roost selection by flying foxes. This factor explains why males, females and females with young may prefer different camp environments (Hamilton and Barclay 1994). During breeding and lactation periods, females may select warm microclimates within camps in order to reduce the energetic costs of maintaining a high body temperature and facilitate higher rates of juvenile development (McNab 1982), thereby increasing the fitness of both the mother and her offspring (Entwistle et al. 1997). In contrast, Willis et al. (2006) suggested that cooler camps may benefit breeding females. It is likely that female flying foxes move within the camp to select locations that best suit their reproductive condition and the ambient environmental conditions. As the present study was conducted during GHFF breeding season, the colonies consisted of territorial males and females with and without young; therefore, having a large variance in temperature and humidity could potentially accommodate the needs of all group members in this highly social species.

There are, however, numerous possible explanations as to why the core area of the camp would be significantly more variable than the peripheral areas with respect to both temperature and humidity. Other studies have shown that within enclosed areas such as caves and buildings, clustering bats may be able to elevate the temperature and humidity of a camp via metabolic processes (Burnett and August 1981; Baudinette et al. 1994). Although it is debated whether this is possible for foliage-roosting bats (Willis 2006), as GHFFs roost in large aggregations (Eby 1991b) and close to one another, it is possible that the observed increased temperature is a result of clustering bats emitting heat. Similarly, bats constantly expire water vapour from their mouths (particularly when they pant) and also lick their wings to increase evaporative cooling during hot weather. Thus the presence of tens of thousands of bats in a relatively small area could have a direct impact on the surrounding microclimate. However, the bats are absent from the camp during their nightly foraging bouts, thus much of the data (particularly the minimum temperatures) relate to periods when the bats were not present. Nevertheless, significant microclimate differences still occur between core roost trees and neighbouring peripheral trees overnight, suggesting that the bats are not directly responsible for microclimate differences between locations. 
A far more likely alternative explanation for the differences between locations relates indirectly to the behaviour of the bats. GHFFs cause a considerable amount of defoliation of the selected roosting trees (hence their eviction from the Sydney and Melbourne Botanic gardens), therefore, data loggers within the core roosting areas may have been exposed to direct sunlight, which may increase the temperature recorded by the loggers. The data loggers housed within the periphery of the reserves, in contrast, were located in intact trees, which would limit temperature variation. This indirect effect of the bats on the temperature in the camp is further supported by the greater degree of temperature variation in permanently occupied camps in comparison with the transient camps (Fig. 4). Defoliation of trees in core areas, however, cannot explain the observed pattern in the humidity data. Nevertheless, these differences in foliage coverage still reflect the roosting preferences of the bats, but there is some evidence that the core location of the colony can shift over time (Pallin 2000; Hall 2002). This shift in key roost trees may be in direct response to the change in microclimate variables as the canopy continues to senesce.

Humidity has been shown to play a significant role in the camp selection of many bat species (Churchill 1991; Churchill et al. 1997) and this study suggests that GHFFs may also select camps on the basis of humidity. Our data show that the variance in humidity within camps is over $2 \%$ higher than in the surrounding bushland. While this is a seemingly small difference, it is possible that humidity influences camp selection to a greater extent than reported here because our data were collected during an unusually wet year. The average mean relative humidity recorded in the camps during this study was $72.5 \%$. Independent data collected from weather stations by the Bureau of Meteorology indicated that Sydney experienced above-average rainfall during the study period. Additionally, between 19 November and 10 December 2007, Sydney recorded the most humid three-week period for 20 years and higherthan-average humidity was recorded over the entire study period (Bureau of Meteorology 2008). This unusual and consistently high humidity allowed for only minor distinctions in humidity throughout the Sydney region. Hence it is likely that the true differences within camps and between camps may have been masked. Consequently, additional long-term studies will be required to further understand the role humidity plays in camp selection by GHFFs.

\section{Permanent versus semi-permanent camps}

Microclimatic variables were also different between permanent and transient camps. For example, permanently occupied camps had far greater daily variation in temperature $\left(\sim 8.4^{\circ} \mathrm{C}\right)$ than did transient camps (Fig. 4). The difference between permanent camps and semipermanent camps was often subtle and it depended on the location within the camp. Permanent camps, for example, showed a $1.6^{\circ} \mathrm{C}$ difference in daily maximum temperatures between the camp and the surrounding bushland whereas no difference was observed in temporary camps. Studies on both foliage-roosting and cave-dwelling bats suggest that other variables, such as urban cover (Roberts 2005), human disturbance (Sewall et al. 2003), food abundance (Tidemann et al. 1999), structure of the roosting environment and season (Briggler and Prather 2003) may all be important in determining occupancy of roosting locations. Of all these variables, we suggest that food availability is the strongest factor determining how often a GHFF camp is occupied. If local food rewards are high around transient camp locations, it is likely that bats will be less choosey with respect to camp microhabitat variables in favour of higher food intake, particularly if their presence in the camp is ephemeral.

In summary, microclimate variables in the core areas of permanent camps are slightly more suitable than those in semipermanent camp locations. It is likely that the utilisation of transient camps will largely depend on local food availability with microhabitat suitability traded off for higher food rewards. 
It is predicted that, in the near future, the frequency and intensity of sporadic periods of extreme temperatures will increase and the rainfall along the east coast of Australia will decrease seasonally (Meehl and Tebaldi 2004;CSIROandBoM2007). These climatic changes are likely to affect the habitat availability for many animal species (Parris and Hazell 2005) and has already been shown to have an impact on the current distribution of the GHFF (Parris and Hazell 2005). This species is clearly capable of shifting its distribution southwards, but it has now reached a considerable barrier in the form of Bass Strait. It is unlikely that this species is capable of island hopping to Tasmania, thus the distribution is likely to be compressed. Moreover, recent research indicates that the survival of this and related species is directly linked to extreme temperatures. Flying foxes are highly susceptible to extreme heat events. As temperatures exceed $42^{\circ} \mathrm{C}$ mortality rates dramatically increase (Welbergen et al. 2008). Temperatures of this magnitude are far more common in the coastal fringe of the southern states (Victoria and South Australia) than in the northern states (Queensland and New South Wales), thus the distribution shift is likely to put this species in harm's way. Further, results from a related study (Snoyman et al. unpubl. data) suggest that females with young are the most vulnerable to extreme heat, thus shifts in climatic extremes in response to global warming are likely to be catastrophic for this species.

In addition to the pressures induced by climate change, there is increasing conflict between bats and humans. Camps are increasingly common in Australian cities, with Brisbane, Sydney and Melbourne all home to significant numbers of bats. In many cases, where wildlife comes into conflict with humans, the wildlife loses. This is clearly illustrated by the continued granting of licences to shoot flying foxes in Queensland and the eviction of bats from urban roosts. The latter is exemplified by largescale relocation projects within the SRBG due to vegetation destruction, as well as other forced evictions from established camps such as in the Melbourne Royal Botanic gardens. For a threatened species with limited roosting options, such management plans further threaten the survival of this species.

\section{Acknowledgements}

The authors thank Macquarie University, Ku-ring-gai Bat Conservation Society, DECCC,WWF and Fairfield City Council for funds that covered the cost of this project. Further, we are thankful to both DECCC and Bruce Thomson for the loan of equipment. Thank you to Marjorie Beck, Nancy Pallin, Katie Cabezas, Michael Davis, Peggy Eby, Megan Haberley, Vickii Lett, David Bidwell, Vanessa Wilson, Richard Sheehan, Andrew Smith, Peter Spring, Angela Mateo, Sonya Stanvic, Nicola Markus and Kylie McClelland, who all contributed to this study. Various licenses were obtained before this studywas conducted, including aMacquarie University Animal Ethics licence (2006-022) and a Department of Primary Industries permit licence (512204).

\section{References}

Baldwin, H. (2010). Conservation genetics of the grey-headed flying-fox. B.Sc.(Honours) Thesis, Macquarie University, Sydney.

Baudinette, R. V., Wells, R. T., Sanderson, K. J., and Clark, B. (1994). Microclimatic conditions in maternity caves of the bent-wing bat, Miniopterus schreibersii: an attempted restoration of a former maternity site. Wildlife Research 21, 607-619. doi:10.1071/WR9940607

Baudinette, R. V., Churchill, S. K., Christian, K. A., Nelson, J. E., and Hundon, P. J. (2000). Energy, water balance and the roost microenvironment in three Australian cave-dwelling bats (Microchiroptera). 
Journal of Comparative Physiology. B, Biochemical, Systemic, and Environmental Physiology 170, 439-446. doi:10.1007/s003600000121

Briggler, J. T., and Prather, J. W. (2003). Seasonal use and selection of caves by the eastern pipistrelle bat (Pipistrellus subflavus). American Midland Naturalist 149, 406-412. doi:10.1674/00030031(2003)149[0406:SUASOC]2.0.CO;2 Bureau of Meteorology (2008). Available at: http://www.bom.gov.au

Burnett, C. D., and August, P. V. (1981). Time and energy budget for day-roosting in a maternity colony of Myotis lucifugus. Journal of Mammalogy 62, 758-766. doi:10.2307/1380597

Churchill, S. K. (1991). Distribution, abundance and roost selection of the orange horshoe-bat, Rhinonycteris aurantius, a tropical cave-dweller. Wildlife Research 18, 343-353. doi:10.1071/WR9910343

Churchill, S., Draper, R., and Marais, E. (1997). Cave utilisation by Namibian bats: population, microclimate and roost selection. South African Journal of Wildlife Research 27, 44-50.

CSIRO and BoM (2007). Climate change in Australia. Technical Report 2007. 148 pp. CSIRO, Australia.

Dickman, C., and Fleming, M. (2002). Pest, or passenger pigeon? The New South Wales Scientific Committee's assessment of the status of the grey-headed flying fox. In 'Managing the Greyheaded Flying Fox as a Threatened Species in NSW'. (Eds P. Eby and D. Lunney.) pp. 20-28. (Royal Zoological Society of New South Wales: Sydney.)

Duncan, A., Baker, G. B., and Montgomery, N. (Eds) (1999). 'The Action Plan for Australian Bats.' (Environment Australia: Canberra.) Dwyer, P. D. (1971). Temperature regulation and cavedwelling in bats: an evolutionary perspective. Mammalia 35, 424-455. doi:10.1515/mamm.1971.35.3.424

Eby, P. (1991a). Finger-winged night workers; managing forests to conserve the role of grey-headed flying foxes as pollinators and seed dispersers. In 'Conservation of Australian Forest Fauna'. (Ed. D. Lunney.) pp. 91-100. (Royal Zoological Society: Sydney.)

Eby, P. (1991b). Seasonal movements of grey-headed flying foxes, Pteropus poliocephalus (Chiroptera: Pteropodidae), from two maternity camps in northern New South Wales. Wildlife Research 18, 547-559. doi:10.1071/WR9910547

Eby, P. (1995). Biology and management of Pteropus in New South Wales. Species Report. NSW National Parks and Wildlife Service. Hurstville, Australia.

Eby, P. (2002). Using New South Wales planning instruments to improve conservation and management of grey-headed flying-fox camps. In 'Managing the Grey-headed Flying-fox as a Threatened Species in NSW'. (Eds P. Eby and D. Lunney.) pp. 240-250. (Royal Zoological Society of New South Wales: Sydney.)

Eby, P. (2006). Draft national recovery plan for the grey-headed flying fox Pteropus poliocephalus. NSW Department of Environment and Conservation, Sydney.

Eby, P., and Lunney, D. (2002). Managing the grey-headed flying fox Pteropus poliocephalus as a threatened species: a context for the debate. In 'Managing the Grey-headed Flying-fox as a Threatened Species in NSW'. (Eds P. Eby and D. Lunney.) pp. 1-15. (Royal Zoological Society of New South Wales: Sydney.)

Entwistle, A. C., Racey, P. A., and Speakman, J. R. (1997). Roost selection by the brown long-eared bat Plecotus auritus. Journal of Applied Ecology 34, 399-498. doi:10.2307/2404885

Forsyth, D. M., Scroggie,M.P., andMcDonald-Madden, E. (2006). Accuracy and precision of grey-headed flying fox (Pteropus poliocephalus) flyout counts. Wildlife Research 33, 57-65. doi:10.1071/WR05029

Fujita, M. S., and Tuttle, M. D. (1991). Flying foxes (Chiroptera: Pteropodidae): threatened animals of key ecological and economic importance. Conservation Biology 5, 455-463. doi:10.1111/j.15231739.1991.tb00352.x 
Hall, L. S. (2002). Management of flying fox camps: what have we learnt in the last twenty five years? In 'Managing the Grey-headed Flying-fox as a Threatened Species in NSW'. (Eds P. Eby and D. Lunney.) pp. 215-224. (Royal Zoological Society of New South Wales: Sydney.)

Hall, L. S., and Richards, G. C. (1987). Crop protection and management of flying foxes (Chiroptera: Pteropodidae). Australian Mammalogy 10, 75-81.

Hall, L., and Richards, G. (1991). Flying fox camps. Wildlife Australia 28, 19-22.

Hall, L. S., and Richards, G. (2000). 'Flying Foxes: Fruit and Blossom Bats of Australia.' (University of New South Wales Press: Sydney.)

Hamilton, I. M., and Barclay, R. M. R. (1994). Patterns of daily torpor and day-roost selection by male and female big brown bats (Eptesicus fuscus). Canadian Journal of Zoology 72, 744-749. doi:10.1139/z94-100

IUCN (2010). IUCN Red List of Threatened Species. Version 2010.4. Available at: www.iucnredlist.org

Kalcounis, M. C., and Brigham, R. M. (1998). Secondary use of Aspen cavities by tree-roosting big brown bats. Journal of Wildlife Management 62, 603-611. doi:10.2307/3802336

Kalko, E. K. V., Ueberschaer, K., and Dechmann, D. (2006). Roost structure, modification, and availability in the white-throated roundeared bat, Lophostoma silvicolum (Phyllostomidae) living in active termite nests. Biotropica 38, 398-404. doi:10.1111/j.1744-7429.2006.00142.x

Kerth, G., Weissmann, K., and Konig, B. (2001).Dayroost selection in female Bechstein's bats (Myotis bechsteinii): a field experiment to determine the influence of roost temperature. Oecologia 126, 1-9. doi:10.1007/s004420000489

Kunz, T. H. (1982). Roosting ecology of bats. In 'Ecology of Bats'. (Ed. T. H. Kunz.) pp. 1-55. (Plenum Publishing Corporation: New York.)

Kunz, T. H., and Lumsden, L. F. (2003). Ecology of cavity and foliage roosting bats. In 'Bat Ecology'. (Eds T. H. Kunz and M. B. Fenton.) pp. 3-89. (The University of Chicago Press: Chicago.)

Law, B. S. (1993). Roosting and foraging ecology of the Queensland blossom bat (Syconycteris australis) in north-eastern New South Wales: flexibility in response to seasonal variation. Wildlife Research 20, 419-431. doi:10.1071/WR9930419

Lunney, D., and Moon, C. (1997). Flying foxes and their camps in the rainforest remnants of north-east New South Wales. In 'Proceedings of the Third National Conference on Australian Forest History'. (Ed. J. Dargavel.) pp. 247-277. (Centre for Resource and Environmental Studies, Australian National University: Canberra.)

Markus, N., and Blackshaw, J. K. (2002). Behaviour of the black flying fox Pteropus alecto: 1. An ethogram of behaviour, and preliminary characterisation of mother-infant interactions. Acta Chiropterologica 4, 137-152.

Martin, L., and Mcllwee, A. P. (2002). The reproductive biology and intrinsic capacity for increase of the grey-headed flying fox Pteropus poliocephalus (Megachiroptera), and the implications of culling. In 'Managing the Grey-headed Flying-fox as a Threatened Species in NSW'. (Eds P. Eby and D. Lunney.) pp. 91-108. (Royal Zoological Society of New South Wales: Sydney.)

McDonald-Madden, E., Schreiber, E. S. G., Forsyth, D. M., Choquenot, D., and Clancy, T. F. (2005). Factors affecting grey-headed flying fox (Pteropus poliocephalus: Pteropodidae) foraging in the Melbourne metropolitan area, Australia. Austral Ecology 30, 600-608. doi:10.1111/j.14429993.2005.01492.x

McNab, B. K. (1982). Evolutionary alternatives in the physiological ecology of bats. In 'Ecology of Bats'. (Ed. T. H. Kunz.) pp. 151-200. (Plenum Press: New York.)

Meehl, G. A., and Tebaldi, C. (2004). More intense, more frequent, and longer lasting heat waves in the 21st century. Science 305, 994-997. doi:10.1126/science.1098704

Pallin, N. (2000). Ku-ring-gai flying-fox reserve: habitat restoration project, 15 years on. Ecological Management \& Restoration 1, 10-20. doi:10.1046/j.1442-8903.2000.00003.x 
Parris, K. M., and Hazell, D. L. (2005). Biotic effects of climate change in urban environments: the case of the grey-headed flying fox (Pteropus poliocephalus) in Melbourne, Australia. Biological Conservation 124, 267-276. doi:10.1016/j.biocon.2005.01.035

Parry-Jones, K. (1987). Pteropus poliocephalus (Chiroptera: Pteropodidae) in New South Wales. Australian Mammalogy 10, 81-86.

Peacock, L. (2004). Roost preference of the grey-headed flying fox. Thesis, University of Sydney.

Puddicombe, R. (1981). A behavioural study of the grey headed flying fox (Pteropus poliocephalus). B.Sc.(Honours) Thesis, University of New England, Armidale.

Ratcliffe, J. M., and ter Hofstede, H. M. (2005). Roosts as information centres: social learning of food preferences in bats. Biology Letters 1, 72-74. doi:10.1098/rsbl.2004.0252

Roberts, B. J. (2005). Habitat characteristics of flying fox camps in south-east Queensland. B.Sc.(Honours) Thesis, Griffith University, Brisbane.

Sedgeley, J. A. (2001). Quality of cavity microclimate as a factor influencing selection of maternity roosts by a tree-dwelling bat, Chalinolobus tuberculatus, in New Zealand. Journal of Applied Ecology 38, 425-438. doi:10.1046/j.1365-2664.2001.00607.x

Sewall, B. J., Granek, E. F., and Trewhella, W. J. (2003). The endemic Comoros Islands fruit bat Rousettus obliviosus: ecology, conservation, andRedList status. Oryx 37, 344-352. doi:10.1017/S0030605303000607

Smith, M. (2002). Management of roost sites of the grey-headed glying fox Pteropus poliocephalus on the north coast of NSW: a National Parks and Wildlife Service perspective. In 'Managing the Greyheaded Flyingfox as a Threatened Species in NSW'. (Eds P. Eby and D. Lunney.) pp. 202-214. (Royal Zoological Society of New South Wales: Sydney.)

Snoyman,S. (2008). Micro-climate preferences of the grey-headedflying-fox, Pteropus poliocephalus (Chiroptera: Pteropodidae), within the Sydney Region. B.Sc.(Honours) Thesis, Macquarie University, Sydney.

Tidemann, C. R. (1999). Biology and management of the grey-headed flying fox, Pteropus poliocephalus. Acta Chiropterologica 1, 151-164.

Tidemann, C. R., Vardon, M. J., Loughland, R. A., and Brocklehurst, P. J. (1999). Dry season camps of flying fox (Pteropus spp.) in Kakadu World Heritage Area, north Australia. Journal of Zoology 247, 155-163. doi:10.1111/j.1469-7998.1999.tb00979.x

Turbill, C. (2006). Thermoregulatory behaviour of tree-roosting chocolate wattled bats (Chalinolobus morio) during summer and winter. Journal of Mammalogy 87, 318-323. doi:10.1644/05-MAMM-A167R1.1

Welbergen, J. A. (2005). The social organisation of the grey-headed flying fox, Pteropus poliocephalus. Ph.D. Thesis, University of Cambridge.

Welbergen, J. A., Klose, S. M., Markus, N., and Eby, P. (2008). Climate change and the effects of temperature extremes on Australian flying foxes. Proceedings of the Royal Society, Series B 275, 419-425. doi:10.1098/rspb.2007.1385

Williams, N. S. G., Mcdonnell, M. J., Phelan, G. K., Keim, L. D., and van der Re, R. (2006). Range expansion due to urbanization: increased food resources attract grey-headed flying foxes (Pteropus poliocephalus) to Melbourne. Austral Ecology 31, 190-198. doi:10.1111/j.14429993.2006.01590.x

Willis, C. K. R. (2006). Daily heterothermy by temperate bats using natural roosts. In 'Functional and Evolutionary Ecology of Bats'. (Eds A. Zubaid, G. F. McCracken and T. H. Kunz.) (Oxford University Press:NewYork.)

Willis, C. K. R., and Brigham, R. M. (2004). Roost switching, roost sharing and social cohesion: forestdwelling big brown bats, Eptesicus fuscus, conform to the fission-fusion model. Animal Behaviour 68, 495-505. doi:10.1016/j.anbehav.2003.08.028 
Willis, C., and Brigham, R. M. (2005). Physiological and ecological aspects of roost selection by reproductive female hoary bats (Lasiurus cinerus). Journal of Mammalogy 86, 85-94. doi:10.1644/1545-1542(2005)086<0085:PAEAOR>2.0.CO;2

Willis, C. K. R., and Brigham, R. M. (2007). Social thermoregulation exerts more influence than microclimate on forest roost preferences by a cavity-dwelling bat. Behavioral Ecology and Sociobiology 62, 97-108. doi:10.1007/s00265-007-0442-y

Willis, C. K. R., Voss, C. M., and Brigham, R. M. (2006). Roost selection by forest-living female big brown bats (Eptesicus fuscus). Journal of Mammalogy 87, 345-350. doi:10.1644/05-MAMM-A-118R1.1 